\title{
A new Pattern of CDIO Engineering Education and Application in Mechanical Principle Course
}

\author{
Yang Yong, Jiang Jingliang, Wang Dexiang, Jin Xia \\ School of Mechanical Engineering, Qingdao Technological University, Shandong Qingdao 266520, \\ China
}

Keywords: Engineering education. CDIO. Application pattern. Mechanical principle

\begin{abstract}
As a practice pattern of current international higher engineering education, CDIO has brought significant changes to and impacts on engineering education, which has the remarkable effect on cultivating the abilities of integrative design, innovative practice and team collaboration. But so far, the CDIO pattern has not a wide range of application in China, because of the implementation link which is difficult to come true. To solve this problem, a new application pattern of CDIO engineering education is put forward to, which integrates the core cultivation concept of CDIO and the features of modern laboratory, such as the openness, compatibility, diversity, reusability and renew ability. The CDIO new pattern performs CDIO process, especially the "Implement and Operate" link, using the laboratory resources. Practical application shows that the CDIO engineering education new pattern overcomes the defects brought by conventional CDIO pattern, such as high cost, long time, large human input and slow response to the change plan, and can effectively develop the students' ability of engineering practice and engineering innovation.
\end{abstract}

CDIO (Conceive-Design-Implement-Operate) engineering education pattern is the latest achievement of international engineering education reform in recent years. It takes the product life cycle of research and development as the carrier, letting students take the active and practical way which has a link between classes to study project[1]. So far, dozens of world famous universities have joined the CDIO organization. CDIO embodies the unity of systematic, scientific and advanced, and represents the development trend of contemporary engineering education[2].

$\mathrm{CDIO}$ engineering education pattern has aroused widespread concern in Colleges at home and abroad. Shantou University has done the earliest exploration and practice of CDIO engineering education, and is the pioneer and leader in the application of CDIO engineering education. They goal is to cultivate students' systemic ability of engineering technology in the CDIO engineering education. Especially the concept, design, development and implementation abilities of the project as well as the strong self-learning ability, organizational communication skills and coordination ability[3]. Yanshan University has established a course teaching system that taking the project as the main line, making a training program that taking the design as a guide and the engineering ability training as the goal. They constructing the classification teaching pattern which making the three level project as the leading, letting so many kinds of teaching forms combined with the teaching content, such as the classroom instruction, the experimental teaching, the research discussion, the project implementation and the report competition[4]. Chengdu University of Information Technology draws on the CDIO pattern, forming the integrated reform scheme which taking the specialty construction as the main line in the education and teaching. And they also set up the professional standards and the training programs[5]. Chengdu Neusoft University combines with the teaching concept of CDIO, studying the teaching course reform from three aspects of teaching content, teaching method and course examination. And they put forward a set of teaching methods based on TOPCARES - CDIO[6].

In this paper, based on the thinking and summary about the current situation of domestic CDIO application as well as combined with the concept and characteristics of CDIO pattern, we put forward a new application pattern of CDIO. It systematically expounds the connotation, the application system of the new pattern and so on, and has made practical application in mechanical 
principle courses.

\section{Proposed Concept, Connotation and Advantage of a new Application Pattern of CDIO}

Based on the analysis of the implementation difficulties of CDIO engineering education pattern and the operating conditions of existing laboratory resources, we propose a new application pattern of LAB-CDIO (LABORATORY-CDIO). The LAB-CDIO is the new pattern that running CDIO idea and process in the laboratory environment. And it combines the assembly of the experimental equipment and the simulation process with the idea, the design, the implementation and the operation (CDIO). This pattern is designed through the systemic project of CDIO, relying on the assembly and simulation functions provided by the experimental platform, to achieve the whole process that a product from the idea to run and the purpose that developing and training students' ability of creative design. The idea of the LAB-CDIO pattern is to combine the core training idea of CDIO with the modern laboratory's idea, such as the openness, the accommodation, the diversity, the repeated use and the update. It is a kind of highly effective application pattern which is implemented and ran the CDIO four links (especially supports the realization and operation links) in the laboratory environment. It is a well operated pattern to implement engineering education concept of CDIO, and also is the refinement and the specific embodiment of the CDIO pattern.

Compared with the traditional CDIO pattern, the LAB-CDIO pattern has the following advantages in the following three aspects:

(1) Having a significant advantage in cost and time saving. The LAB-CDIO pattern relying on existing experimental equipment and does not need to repurchase the experimental materials. Therefore, it can save a certain cost and time, and has a good advantage.

(2) Having a significant advantage in project adaptability. Whether it is the one-level project, two-level project or three-level project, the training objectives and contents of the project are always changing. For conventional CDIO pattern, it is necessary to re carry in the design of project and physical production process. However, the LAB-CDIO pattern can be used the basic platform that having been built to complete the updated project training. So the adaptability for the project is much better than the conventional CDIO pattern.

(3) Can give full play to the efficacy and potential of experimental equipment. At present, the utilization rate of laboratory equipment should be improved in Colleges, and LAB-CDIO pattern combines the experimental equipment with the engineering education training of CDIO. So it can make full use of laboratory equipment.

\section{Practice Process Of a new Application Pattern of CDIO}

According to the CDIO implementation steps, the practice process of LAB - CDIO is as follows:

(1)Designing LAB - CDIO project according to different courses and teaching objectives;

(2)Conception and design according to project goals, then putting forward the solution;

(3)Choosing experimental equipment and components to arrange the experiments;

(4)Through the experiment equipment and assemble of components, system building, or equipment processing to execute the link of "Implement";

(5)Through the operation demonstration and the repeated correction of the experimental system to execute the link of "Operate" ;

(6)Through project defense, communication and ability assessment to complete the LAB-CDIO training project.

\section{Application of a new Pattern of CDIO in Mechanical Principle}

Different gear train is thought to be a difficulty in mechanical principle course, thus "different mechanism" three-level project is designed to solve this difficulty. A new pattern of CDIO proposed in the paper is applied to this three-level project and specific process of application is as follows: 
(1) Design of "Differential" Three-level Course Project. Various typical mechanisms and components are used to design the system of differential in automobile rear bridge and electric motor is served as prime motor. One link's motion is decomposed into two links' in changeable ratio, so in terms of different driving states two rear-wheels of automobile will adjust rotate speed automatically to decrease the slide between tire and ground.

(2) Conceive、Design and Proposing Solutions. There are many kinds of solutions, according to students' designs, an example is given as follows.

When motion of electric motor 1 is transmitted to spur gear set 4 through v-belt 2, its speed is slow then the motion is transmitted to rear axle differential 6 through universal coupling 5 . Meanwhile, differential gear train is equipped with angular displacement sensors 7 and 9 in both sides and driving spur gear is equipped with angular displacement sensor 3, so their movement rules can be analyzed by tests. With the help of this transmission scheme, students can master working principle and movement rule of rear axle differential.

(3) Arrangement of Laboratory Equipment and components. Laboratory table which is used to innovative design 、assembly and simulation of gear train comes to use. This equipment is used to design 、 analyze and apply and students' abilities which are relevant to innovative design 、 comprehensive design and practice can be cultivated and raised by assembly and simulation of gear train. Electric motor、v-belt、gear、key v coupling、screwed fittings and stand and so on are used to build the table and component.

(4) Assembly and Building of Laboratory Equipment and Components. According to transmission scheme, students participate in assembly and building of differential system personally by using equipment and components mentioned above. Figure 1 and 2 show respectively the process of assembly and the objects of differential system .

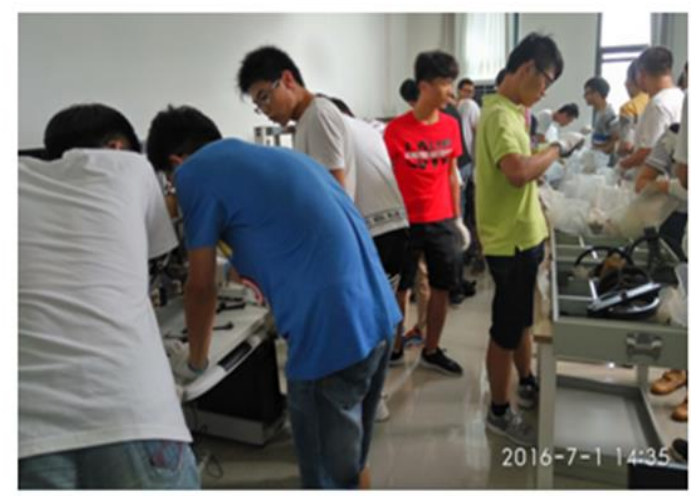

FIGURE 1 Process of assembly and building

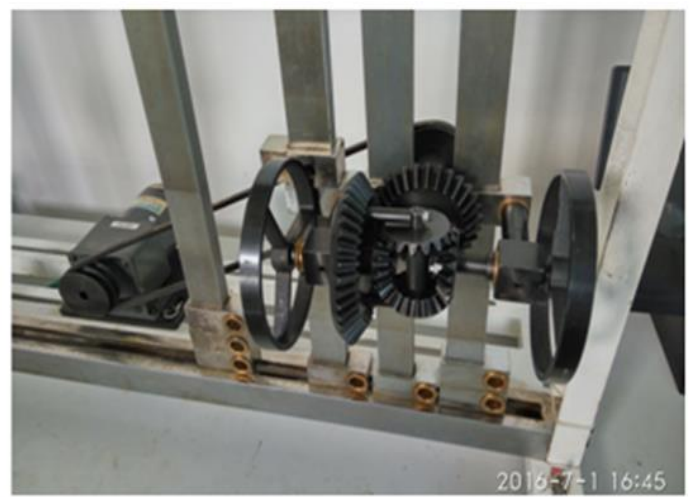

FIGURE 2 Differential system after assembled

(5) Operation of Differential System and Correction and Improvement of Scheme. Differential system is operated in laboratory table and its various parameters are regulated. Transmission scheme is amended repeatedly until it is prefect. By testing and analyzing the movement of system students master the function of differential, furtherly they have a deeper comprehension to different gear train and have a acquaintance with engineering application of it.

(6) Project's Defense、Exchange and Assessing Ability. Students will be divided into groups after completing the operation of project. Each group make PPT to defense、 exchange the process and experience of scheme's design and submit report of design and then each project will be marked.

\section{Summary}

(1)In the light of the "physical production" problem that restricting the development of CDIO engineering education, we put forward the new application pattern of education. It carries out practice of CDIO engineering education in the laboratory environment, and uses laboratory 
resources to solve the problem of the "physical production". Then the connotation, advantage and implementation process of the new pattern of CDIO engineering education are further discussed. In the end, the new pattern of CDIO engineering education is applied in the three-level project of mechanical principle.

(2) The practical application shows that it is feasible to use the laboratory resources to carry out the CDIO process. Compared with the conventional CDIO engineering education pattern, the new pattern of CDIO engineering education has better applicability and stronger operability. At the same time, in the training of students' engineering design ability, engineering innovation ability and engineering practice ability also has a good effect, and can achieve the goal of CDIO engineering education.

(3) The new LAB-CDIO pattern proposed in this paper is a new practice pattern that is different from the conventional idea. It orients the whole teaching process, such as the theory teaching, the experiment teaching, the course design, the graduation design and the engineering training teaching. And using the existing laboratory resources to solve the problem of "physical production", so it has advantage in the wide range of application.

\section{Acknowledgements}

This work was financially supported by the Key projects of construction engineering education reform of higher education schools in Shandong Province (MX4 - 003).

\section{Reference}

[1] F. Edward: Re understanding of Engineering Education - International CDIO training mode and method (Higher Education Press, China 2009).

[2] H. Lei huan, W.Y. Tang and F. Edward: Higher Engineering Education Research, Vol. 5 (2009), p. 29 - 35.

[3] P. H. Gu: Higher Engineering Education Research, Vol. 3(2012), p.24-40.

[4] Y.G. Shi, X. Wang and J.T. Yao: Teaching Research, Vol. 38(2015), p. 77 - 81.

[5] T. B. Wang, W. D. Cheng: Higher Engineering Education Research, Vol. 1(2010), p. 25 - 31.

[6] L. Luo Li, P. Huang: Industry and Technology Forum, Vol. 15(2016), p. 140 - 141. 